\title{
Polyethyleneimine-Oleic Acid Micelles-Stabilized Palladium Nanoparticles as Highly Efficient Catalyst to Treat Pollutants with Enhanced Performance
}

\author{
Xiang Lai ${ }^{1,+}$, Xuan Zhang ${ }^{1,+}$, Shukai Li ${ }^{1}$, Jie Zhang ${ }^{1}$, Weifeng Lin ${ }^{2}$ and Longgang Wang ${ }^{1, *}$ \\ 1 Key Laboratory of Applied Chemistry, Hebei Key Laboratory of Heavy Metal Deep-Remediation in \\ Water and Resource Reuse, College of Environmental and Chemical Engineering, Yanshan University, \\ Qinhuangdao 066004, China; 1x0406x@163.com (X.L.); 15603395687@163.com (X.Z.); \\ lishukai1998@163.com (S.L.); 19991641458@163.com (J.Z.) \\ 2 Department of Molecular Chemistry and Materials Science, Weizmann Institute of Science, \\ Rehovot 76100, Israel; lin.weifeng@weizmann.ac.il \\ * Correspondence: lgwang@ysu.edu.cn \\ + These authors contributed equally to this work.
}

check for updates

Citation: Lai, X.; Zhang, X.; Li, S.; Zhang, J.; Lin, W.; Wang, L.

Polyethyleneimine-Oleic Acid Micelles-Stabilized Palladium Nanoparticles as Highly Efficient Catalyst to Treat Pollutants with Enhanced Performance. Polymers 2021, 13, 1890. https://doi.org/ $10.3390 /$ polym 13111890

Academic Editor: M. Ali Aboudzadeh

Received: 28 April 2021

Accepted: 2 June 2021

Published: 6 June 2021

Publisher's Note: MDPI stays neutral with regard to jurisdictional claims in published maps and institutional affiliations.

Copyright: (c) 2021 by the authors. Licensee MDPI, Basel, Switzerland. This article is an open access article distributed under the terms and conditions of the Creative Commons Attribution (CC BY) license (https:/ / creativecommons.org/licenses/by/ $4.0 /)$.

\begin{abstract}
Water soluble organic molecular pollution endangers human life and health. It becomes necessary to develop highly stable noble metal nanoparticles without aggregation in solution to improve their catalytic performance in treating pollution. Polyethyleneimine (PEI)-based stable micelles have the potential to stabilize noble metal nanoparticles due to the positive charge of PEI. In this study, we synthesized the amphiphilic PEI-oleic acid molecule by acylation reaction. Amphiphilic PEI-oleic acid assembled into stable PEI-oleic acid micelles with a hydrodynamic diameter of about $196 \mathrm{~nm}$ and a zeta potential of about $34 \mathrm{mV}$. The PEI-oleic acid micelles-stabilized palladium nanoparticles ( $\mathrm{PO}-\mathrm{PdNPs}_{\mathrm{n}}$ ) were prepared by the reduction of sodium tetrachloropalladate using $\mathrm{NaBH}_{4}$ and the palladium nanoparticles (PdNPs) were anchored in the hydrophilic layer of the micelles. The prepared PO-PdNPs $s_{n}$ had a small size for PdNPs and good stability in solution. Noteworthily, PO-PdNPs 150 had the highest catalytic activity in reducing 4-nitrophenol (4-NP) $\left(K_{n o r}=18.53 \mathrm{~s}^{-1} \mathrm{mM}^{-1}\right)$ and oxidizing morin $\left(K_{\text {nor }}=143.57 \mathrm{~s}^{-1} \mathrm{M}^{-1}\right)$ in aqueous solution than other previous catalysts. The enhanced property was attributed to the improving the stability of PdNPs by PEI-oleic acid micelles. The method described in this report has great potential to prepare many kinds of stable noble metal nanoparticles for treating aqueous pollution.
\end{abstract}

Keywords: polyethyleneimine; micelles; palladium; nanoparticles; catalytic

\section{Introduction}

The quality of water is highly related with our health. Many countries have strictly controlled the emissions of various organic pollutants in water [1]. For example, 4-nitrophenol (4-NP) is highly toxic, but its reduced product 4-aminophenol (4-AP) is relatively low in toxicity and is a pharmaceutical intermediate. The catalytic reduction of 4-NP and similar phenol compounds is carried out on catalysts treated with $\mathrm{NaBH}_{4}$. In addition, morin is a kind of polyphenol dye that belongs to flavonoid dyes. Morin has been used as a model matrix for the study of catalytic bleaching processes in laundry detergents [2,3]. Morin can be degraded by using nanoparticles with $\mathrm{H}_{2} \mathrm{O}_{2}$. These nanoparticles play an important role for the catalytic generation of reactive oxygen species from decomposition of $\mathrm{H}_{2} \mathrm{O}_{2}$. Thus, the efficiency of treatment of organic pollutants is highly dependent on the property of catalysts.

Many kinds of noble metal nanoparticles, such as platinum nanoparticles (PtNPs) [4], gold nanoparticles (AuNPs) [5,6], and palladium nanoparticles (PdNPs) [7-9], catalyze the reduction of 4-NP and the oxidation of morin. The catalytic activity of noble metal nanoparticles is highly dependent on the active atoms on their surface, which results 
in extremely high surface energy of the nanoparticles [10,11]. However, it is for this reason that the nanoparticles are easily agglomerated in the preparation and catalytic reaction process [12], which results in a significant decrease in the number of surface-active atoms and the catalytic activity. This problem limits noble metal nanoparticles in practical applications [13]. Researchers have developed a variety of stabilizers to prevent the coagulation of noble metal nanoparticles, thereby increasing their catalytic efficiency $[14,15]$. For example, Pitchaimani Veerakumar and his colleagues report a method for immobilizing PdNPs $\left(\mathrm{Pd} / \mathrm{NH}_{2}-\mathrm{SiO}_{2}\right)$ with PEI $(\mathrm{Mw}=25,000)$ functionalized silica nanoparticles that have good separation properties and exhibit excellent catalytic performance [16]. As a kind of polymer, PEI has a good advantage as a stabilizer. Each unit with three atoms in the PEI skeleton has a nitrogen atom [17]. Since PEI has a positive charge, it generates electrostatic attraction with the negatively charged noble metal precursor [18], thereby stabilizing the noble metal nanoparticles. However, it is difficult for the low-molecule-weight PEI to stabilize the noble metal nanoparticles. The micelles formed by amphiphilic molecules based on the reaction of low-molecule-weight PEI with other hydrophobic molecules can be one method to stabilize noble metal nanoparticles and solve the shortcomings of low-molecule-weight PEI.

Herein, PEI-oleic acid micelle-stabilized PdNPs $\left(\mathrm{PO}^{\mathrm{PdNPs}} \mathrm{n}\right.$ ) were prepared by using PEI-based micelles. The amphiphilic molecule consisted of low-molecule-weight PEI $(\mathrm{Mw}=600)$ as hydrophilic moiety and oleic acid as hydrophobic moiety. PEI and oleic acid are also inexpensive and readily available. The prepared PdNPs were small in size and had a narrow size distribution. The PO-PdNPs $n$ showed high stability and an enhanced catalytic efficiency to treat pollutants such as 4-NP and morin. The current work provides new ideas for the synthesis of noble metal nanoparticle catalysts with amphiphilic molecular micelles to treat pollutants.

\section{Materials and Methods}

\subsection{Preparation of PEI-Oleic Acid Micelles}

The synthesis of PEI-oleic acid refers to the method reported in the previous literature [17]. First, $0.60 \mathrm{~g}$ PEI, $0.28 \mathrm{~g}$ oleic acid, $0.40 \mathrm{~g}$ EDC. $\mathrm{HCl}, 0.27 \mathrm{~g} \mathrm{HOBt}$, and $6 \mathrm{~mL}$ of anhydrous dimethyl formamide were added into a flask and passed through with $\mathrm{N}_{2}$ for $0.5 \mathrm{~h}$. The obtained solution was dialyzed against methanol with a dialysis bag $(\mathrm{MWCO}=500)$ after 1 day. Then, the PEI-oleic acid was obtained by the removal of methanol with the help of a rotary evaporator (RE-52A, Shanghai Yarong Biochemical Instrument Factory, Shanghai, China). PEI-oleic acid in methanol solution was added dropwise to water (methanol: $\mathrm{H}_{2} \mathrm{O}=1: 9$ ) at $25^{\circ} \mathrm{C}$ for $10 \mathrm{~min}$. The PEI-oleic acid micelles solution was obtained by dialysis.

\subsection{Preparation of $P O-P d N P s_{n}$}

Two $\mathrm{mM} \mathrm{Na}_{2} \mathrm{PdCl}_{4}$ and the PEI-oleic acid micelles were mixed. The molar ratios of $\mathrm{N}$ atoms of the PEI-oleic acid micelles to $\mathrm{Pd}$ atoms of $\mathrm{Na}_{2} \mathrm{PdCl}_{4}$ were 75,100 , and 150, respectively. After $20 \mathrm{~min}$, a 5-fold molar excess of $\mathrm{NaBH}_{4}$ in $0.3 \mathrm{M} \mathrm{NaOH}$ was added. One $\mathrm{M} \mathrm{HCl}$ was added to tune the $\mathrm{pH}$ to neutral after $20 \mathrm{~min}$. The mixed solution reacted for $1 \mathrm{~h}$ to obtain PO-PdNPs $n$

\subsection{Critical Micelles Concentration Measurement}

The critical micelle concentration of the PEI-oleic acid micelles in aqueous solution was determined by a pyrene fluorescence probe [19]. Briefly, the fluorescence intensity values of $374 \mathrm{~nm}$ and $384 \mathrm{~nm}$ at the excitation wavelength of $334 \mathrm{~nm}$ were measured by fluorescence spectrophotometer. The CMC value of the PEI-oleic acid micelles in water was determined by the ratio of fluorescence intensity at $374 \mathrm{~nm}$ and $384 \mathrm{~nm}$. 


\subsection{Catalytic Reaction on 4-NP}

To study the degradation of 4-NP over time, $250 \mu \mathrm{L}$ of 4-NP solution $(600 \mu \mathrm{M}), 1 \mathrm{~mL}$ of water, and $1 \mathrm{~mL}$ of fresh $\mathrm{NaBH}_{4}$ solution $(0.5 \mathrm{M})$ were added in a quartz cuvette $\left(1 \times 1 \mathrm{~cm}^{2}\right)$ in sequence at $25^{\circ} \mathrm{C}$. Then, $50 \mu \mathrm{L}$ of PO-PdNPs $75(8.35 \mu \mathrm{M})$ was added. UV-Vis spectra within $200-800 \mathrm{~nm}$ of the mixed solution were recorded every $3 \mathrm{~min}$.

To explore the relationship between PO-PdNPs $n$ and the catalytic rate, $250 \mu \mathrm{L}$ of 4-NP $(600 \mu \mathrm{M})$ solution, water, and $1 \mathrm{~mL}$ of fresh $\mathrm{NaBH}_{4}$ solution $(0.5 \mathrm{M})$ were added into a quartz cuvette followed by the addition $50 \mu \mathrm{L}$ of PO-PdNPs $(n=75,100,150)$, respectively. The absorbance at $400 \mathrm{~nm}$ was measured by UV-TU1810 (Beijing Purkinje General Instrument Co., Ltd., Beijing, China).

\subsection{Catalytic Reaction on Morin}

Eighty $\mu \mathrm{L}$ of morin in a carbonate buffer at $\mathrm{pH} 9.2(3 \mathrm{mM}), 1790 \mu \mathrm{L}$ of carbonate buffer at $\mathrm{pH} 9.2,50 \mu \mathrm{L}$ of PO-PdNPs 5 ( $0.475 \mathrm{mM})$, and $80 \mu \mathrm{L}$ of hydrogen peroxide $(0.4 \mathrm{mM})$ were added to the cuvette. UV-Vis spectra within $200-800 \mathrm{~nm}$ of the mixed solution were recorded every $2 \mathrm{~min}$. As the same time, the spectra of the control experiment were measured every $5 \mathrm{~min}$.

The effects of different catalyst concentrations and different morin concentrations on the catalytic reaction were determined by UV-TU1810 (Beijing Purkinje General Instrument Co., Ltd., Beijing, China) at $403 \mathrm{~nm}$. One $\mathrm{mM}$ morin, carbonate buffer, PO-PdNPs ( $n=75,100,150)$, and $0.4 \mathrm{M}$ hydrogen peroxide were added to a cuvette. The final concentration of $[\mathrm{N}]$ in $\mathrm{PdNPs}_{\mathrm{n}}$ and hydrogen peroxide were $7.8 \mathrm{mM}$ and $10 \mathrm{mM}$, respectively. The concentration of morin was from 0.5 to $1.25 \mathrm{mM}$. The next experiment had similar procedure. The concentration of $[\mathrm{N}]$ in the catalyst was fixed at $0.78-5.47 \mathrm{mM}$ with $3 \mathrm{mM}$ morin.

\subsection{Statistical Analysis}

The $k_{\text {app }}$ data of the PO-PdNPs $n$ of 4-NP and the morin treatment were analyzed by SPSS 25 to assess the statistical differences between the groups. $p<0.05$ is considered statistically significant.

\section{Results}

\subsection{Characterization of PEI-Oleic Acid Micelles}

Acylation reaction was employed into the synthesis of the amphiphilic molecules of PEI-oleic acid, which is illustrated in Figure 1 . In this reaction, PEI $(\mathrm{Mw}=600)$ and oleic acid had the same amount, EDC. $\mathrm{HCl}$ and $\mathrm{HOBt}$ acted as coupling reagents in dry DMF at room temperature for $24 \mathrm{~h}$ in the acylation reaction. The prepared PEI-oleic acid amphiphilic molecule had PEI as the hydrophilic segment and oleic acid as the hydrophobic segment.

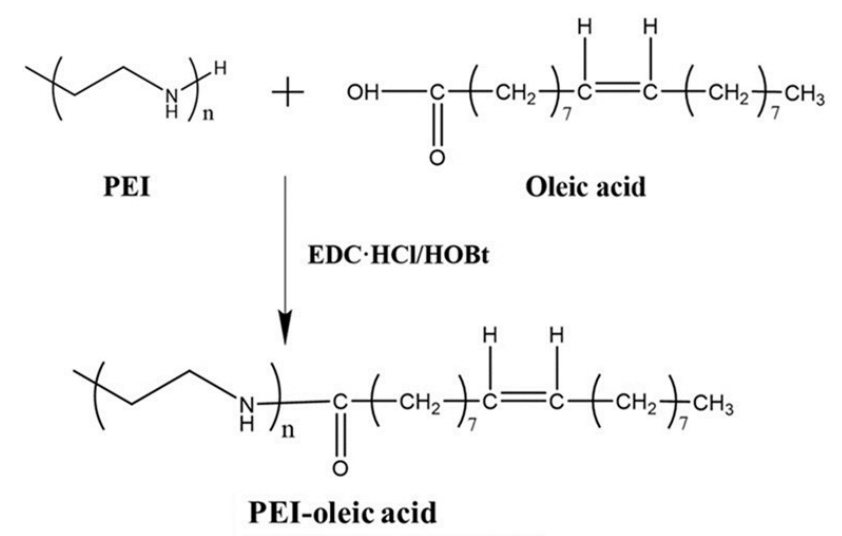

Figure 1. Synthesis of amphiphilic molecule PEI-oleic acid. 
The PEI-oleic acid amphiphilic molecules self-assembled in water to form micelles, and the hydrophilic PEI segment acted as a shell layer of the micelles. The critical micelle concentration $(\mathrm{CMC})$ of the PEI-oleic acid micelles was $[\mathrm{N}]=0.12 \mathrm{mg} / \mathrm{mL}$ based on the fluorescence method using pyrene. The hydrodynamic diameter and zeta potential of PEI-oleic acid micelles were determined to be $196 \mathrm{~nm}$ and $34 \mathrm{mV}$ by DLS (DLS, Malvern, Worcestershire, UK), respectively. The positive charge of the micelles was attributed to the hydrophilic PEI shell.

\subsection{Characterization of $\mathrm{PO}-\mathrm{PdNP} \mathrm{s}_{n}$}

To prepare PO-PdNPs, $\mathrm{Na}_{2} \mathrm{PdCl}_{4}$ was mixed with PEI-oleic acid micelles and then further reduced with $\mathrm{NaBH}_{4}$. As shown in Figure 2a, two characteristic absorption peaks at 305 and $420 \mathrm{~nm}$ were detected for the $\mathrm{Na}_{2} \mathrm{PdCl}_{4}$. After the reduction of $\mathrm{Na}_{2} \mathrm{PdCl}_{4}$ by $\mathrm{NaBH}_{4}$ to produce PdNPs, a new absorption spectrum appeared, which indicated the formation of PdNPs. This was consistent with the results reported in the previous literature [20]. As the molar ratio of $[\mathrm{N}]:[\mathrm{Pd}]$ ranged from 75 to 150 , the color of solution gradually decreased as shown in Figure $2 \mathrm{~b}$. The UV-Vis spectra and color change of solution indicated that the PdNPs were successfully stabilized by the PEI-oleic acid micelles. The positively charged PEI shell played an important role in adsorbing and stabilizing PdNPs. As shown in Figure S1 and Table S1, the infrared spectroscopy has shown the successful preparation of PEI-oleic acid micelles and PO-PdNPs75.
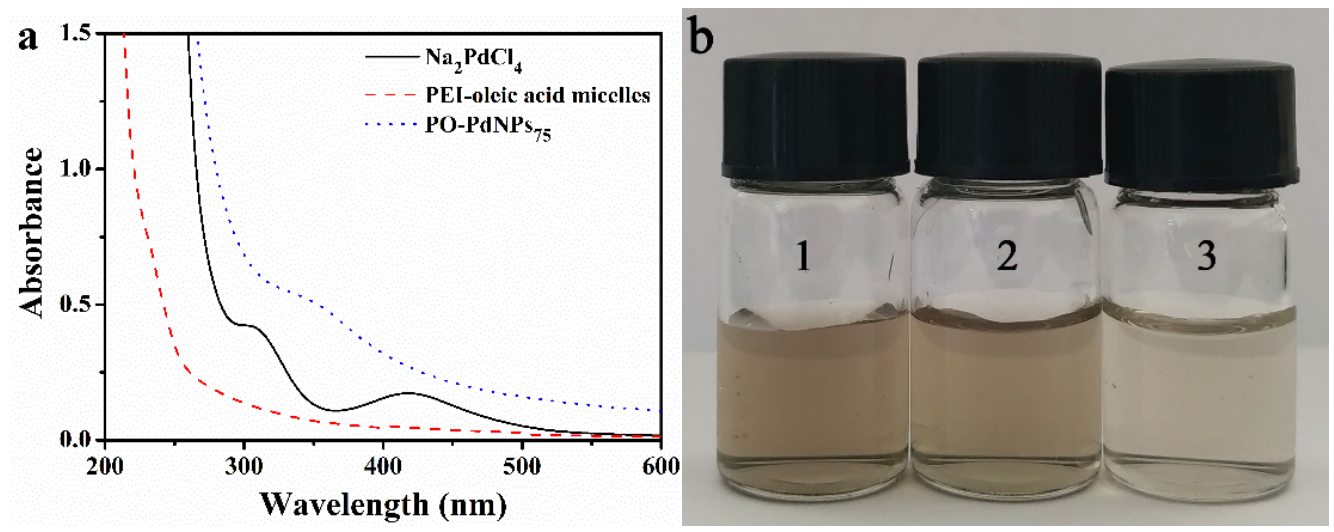

Figure 2. (a) UV-Vis spectra of $\mathrm{Na}_{2} \mathrm{PdCl}_{4}$, PEI-oleic acid micelles, and PO-PdNPs $\mathrm{s}_{75}$, (b) PO-PdNPs with molar ratio of $n=[\mathrm{N}]$ : [Pd] $=75(\mathbf{b} 1), 100(\mathbf{b} 2)$, and $150(\mathbf{b} 3)$, respectively.

The size of the PdNPs of PO-PdNPs $n$ was measured by TEM (TEM, JEM-1230EX, Hitachi, Tokyo, Japan). Figure 3 displays the monodispersed characteristic of PO-PdNPs . The mean particle sizes of PdNPs within PO-PdNPs $s_{n}$ at $[\mathrm{N}]:[\mathrm{Pd}]=75,100$, and 150 were $2.01 \pm 0.30,1.85 \pm 0.25$, and $1.67 \pm 0.27 \mathrm{~nm}$, respectively. The size of the PdNPs decreased with the increasing the molar ratio of $[\mathrm{N}]:[\mathrm{Pd}]$. In short, the prepared PdNPs of PO-PdNPs had a small particle size and a narrow size distribution.

In order to determine the stability of the prepared PO-PdNPs $\mathrm{n}$ in aqueous solution, the hydrodynamic diameter and zeta potential were measured by DLS (DLS, Malvern, Worcestershire, UK) [21,22]. As shown in Figure 4a, the hydrodynamic diameters were about $53.89,43.95$, and $37.86 \mathrm{~nm}$ at a molar ratio of $[\mathrm{N}]:[\mathrm{Pd}]=75,100$, and 150, respectively. These hydrodynamic diameters of the prepared PO-PdNPs were smaller than that of the PEI-oleic acid micelles, which should be attributed to PdNPs located in the PEI-oleic acid micelles' shell. The measured hydrodynamic diameters of the prepared PO-PdNPs was larger than the TEM particle size measured in the dry state $[23,24]$. Figure $4 \mathrm{~b}$ showed that the zeta potential of PO-PdNPs $\mathrm{n}$ was 21.5, 25.55, and $31.1 \mathrm{mV}$ at a molar ratio of $[\mathrm{N}]:[\mathrm{Pd}]=75,100$, and 150, respectively. The positive charge on the surface of PO-PdNPs was larger than $20 \mathrm{mV}$. Thus, the strong electrostatic repulsion was good for the high 
stability of PO-PdNPs $n$ in aqueous solution. In summary, PO-PdNPs ${ }_{n}$ had high stability in solution and big positive charge, so it kept from coagulation within one month.
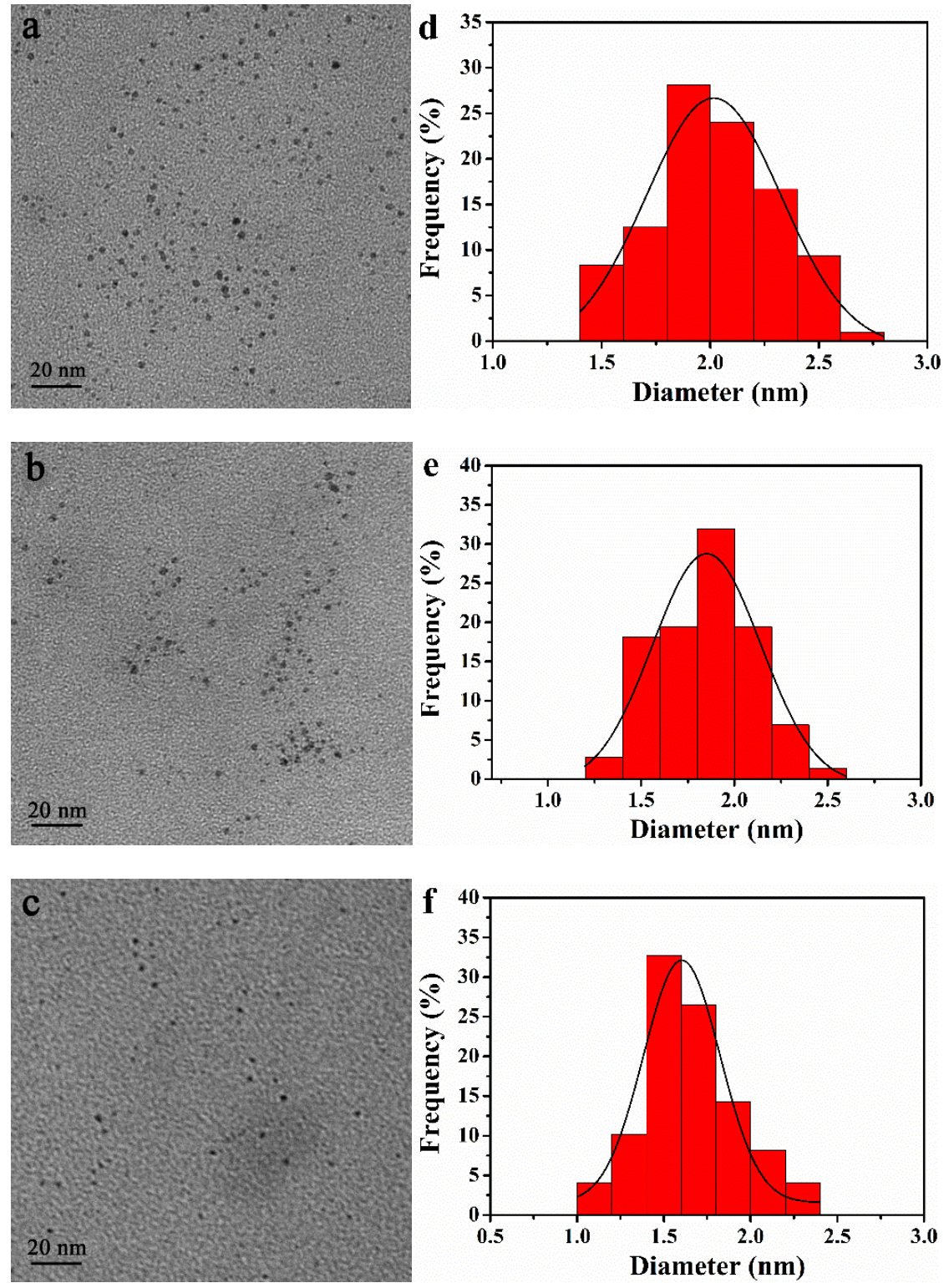

Figure 3. TEM images and size distribution analysis of the PdNPs of PO-PdNPsn: (a,d) $n=75$, (b,e) $n=100,(\mathbf{c}, \mathbf{f}) n=150$.
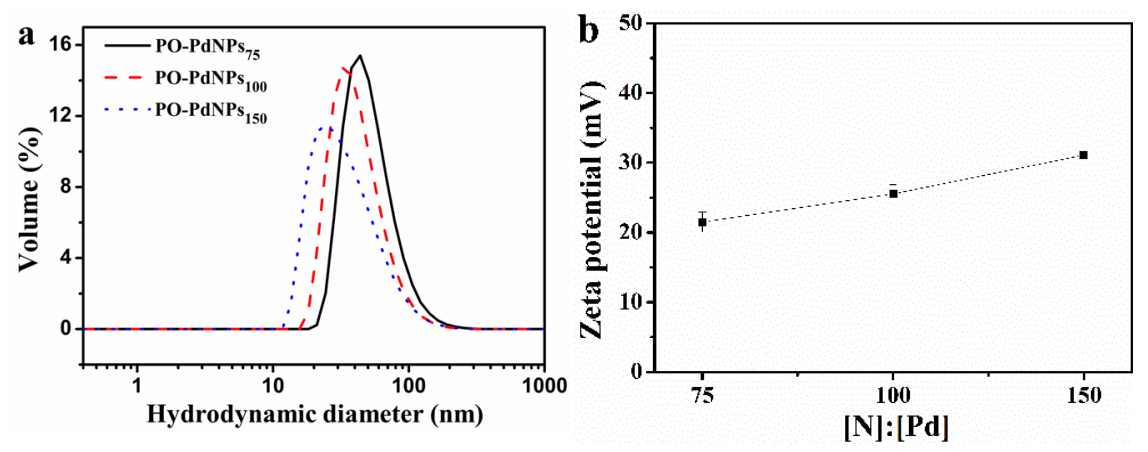

Figure 4. (a) Hydrodynamic diameter and (b) zeta potential of PO-PdNPs $s_{n}$. 


\subsection{Catalytic Activity of PO-PdNPs $s_{n}$ on 4-NP}

The catalytic reduction of 4-NP was employed to evaluate the catalytic activity of PO-PdNPs $s_{n}$. Due to the high toxicity of 4-NP and its pollution of water resources, it has attracted great attention. 4-AP is the reduction product of 4-NP. 4-AP has low toxicity and important applications in industry. It is important to study the method to transform 4-NP into 4-AP. The concentration of PdNPs in the solution of the reacting mixture was as low as $10^{-7} \mathrm{mM}$. Therefore, the absorption spectra of PdNPs almost had no effect on the absorbance of the mixed solution. The absorption peak of 4-NP existed at $317 \mathrm{~nm}$. When the $\mathrm{NaBH}_{4}$ solution was added, the color of the solution rapidly turned yellow, and the obvious absorption peak appeared at $400 \mathrm{~nm}$, which corresponded to 4-hydroxyaminophenol [25]. In Figure 5a, it was found that the absorption peak at $400 \mathrm{~nm}$ decreased gradually, and the absorption peak at $310 \mathrm{~nm}$ increased. The results indicated the formation of 4-AP due to the consumption of 4-hydroxyaminophenol. After $12 \mathrm{~min}$, the color of the solution became colorless, and the absorption peak at $400 \mathrm{~nm}$ decreased to 0.119 as shown in Figure $5 \mathrm{~b}$, indicating that 4-NP completely changed to 4-AP. The turnover frequency (TOF) was defined as the number of reactants converted per h. The TOF of PO-PdNPs 75 reached $1796.4 \mathrm{~h}^{-1}$ in this experiment.
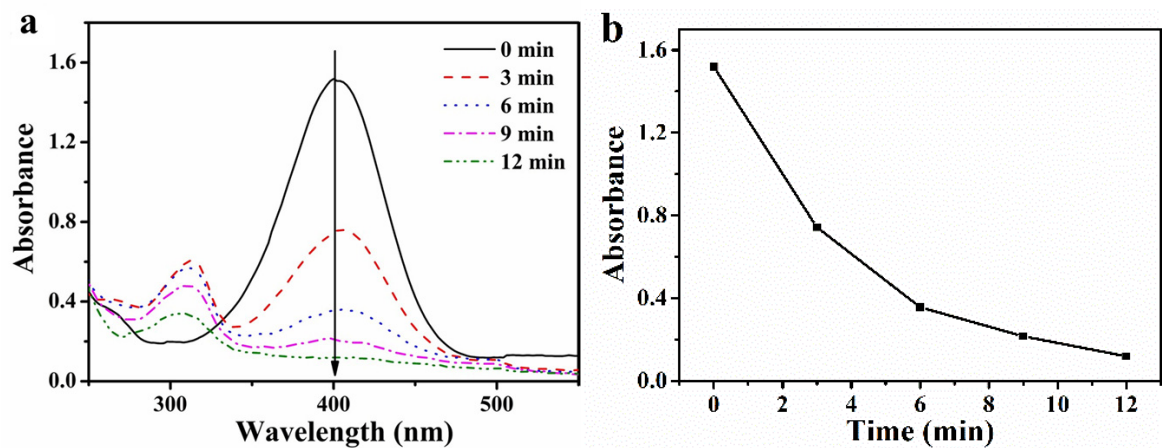

Figure 5. (a) The UV-Vis spectra of the reduction process of 4-NP catalyzed by PO-PdNPs 75 , (b) the relationship diagram of absorbance and time.

As shown in Figure 6a-c, PO-PdNPs $(n=75,100$, and 150) had a linear relationship between $\ln \left(C_{t} / C_{0}\right)$ and reaction time $(\mathrm{t})$. Thus, the catalytic reduction of $4-\mathrm{NP}$ by using PO-PdNPs ${ }_{n}$ followed pseudo-first-order kinetics. This was attributed to excess $\mathrm{NaBH}_{4}$ in the mixed solution. Thus, the apparent rate constant $\left(k_{\mathrm{app}}\right)$ was calculated as follows:

$$
\frac{d C_{t}}{d t}=\ln \left(C_{t} / C_{0}\right)=-k_{a p p} t
$$

The $k_{\text {app }}$ values were calculated from the slope of the lines as shown in Figure 7. The corresponding $k_{\text {app }}$ was shown in Figure $6 \mathrm{~d}$. The $k_{\text {app }}$ value increased with increasing catalyst concentration of $\mathrm{PO}-\mathrm{PdNPs}_{\mathrm{n}}$, indicating that the reduction rate was linear correlated with the concentration of PO-PdNPs $s_{n} K_{n o r}$ was used to compare the catalytic activity of different catalysts, $K_{n o r}$ was defined as the ratio of $k_{\text {app }}$ to molar concentration of catalyst $\left(K_{n o r}=k_{\text {app }} / C_{c a t}\right)$. PO-PdNPs 150 had the highest $K_{\text {nor }}\left(18.53 \mathrm{~s}^{-1} \mathrm{mM}^{-1}\right)$ in PO-PdNPs $\mathrm{n}$. Table 1 shows the $K_{n o r}$ and the TOF of the PO-PdNPs $n$ and other catalysts. PO-PdNPs ${ }_{150}$ had the highest $K_{n o r}$, indicating that they had the highest activity. PdNPs were located in the micelles' shells, which may contribute to their high catalytic activity caused by the low mass transfer resistance of the substrates. In short, this catalytic reaction followed pseudo-first-order kinetics and PO-PdNPs 150 had the highest activity. 

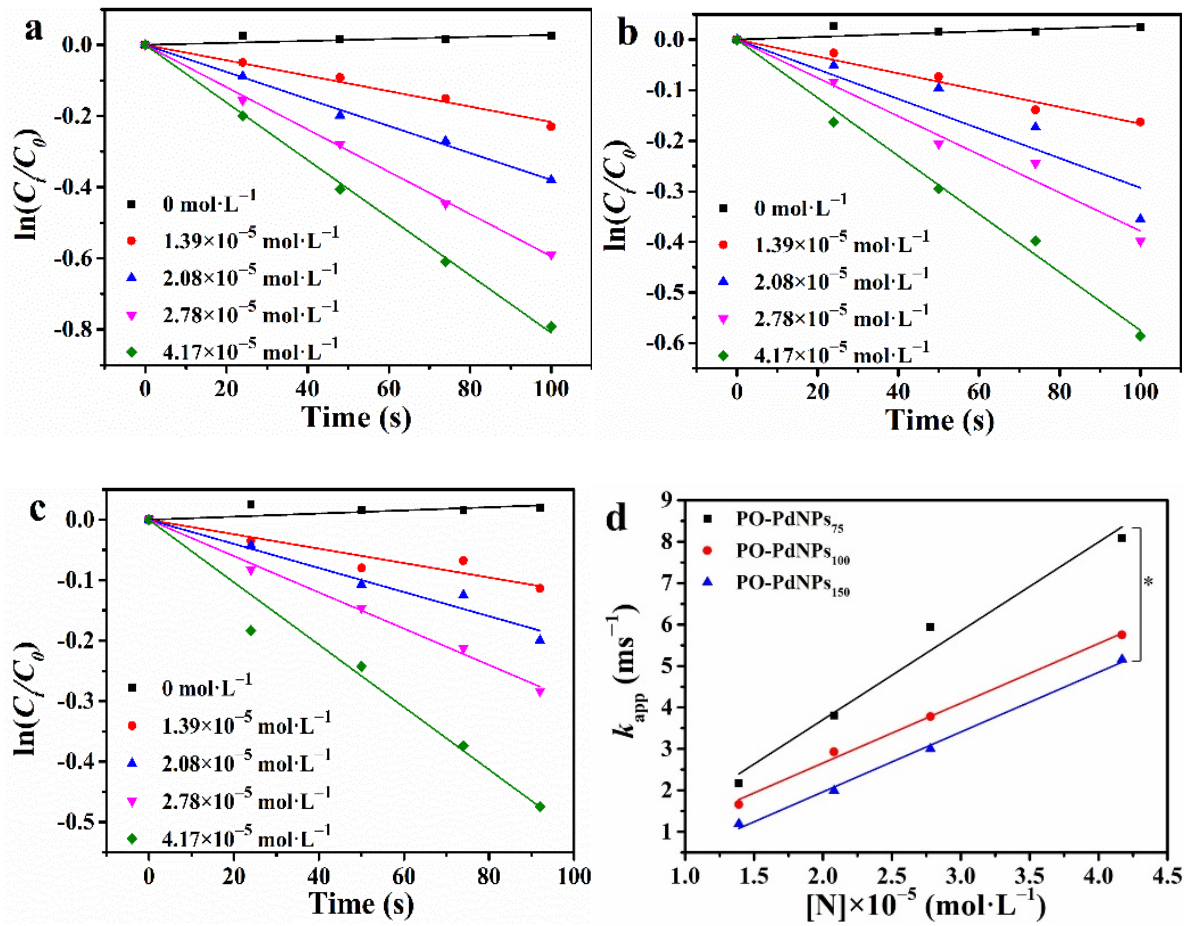

Figure 6. The catalytic process for $\ln \left(C_{t} / C_{0}\right)$ and time (a) PO-PdNPs $s_{75}$, (b) PO-PdNPs $s_{100}$, (c) PO$\mathrm{PdNPs}_{150},(\mathbf{d})$ the linear relationship between $k_{\mathrm{app}}$ and concentration of PO-PdNPs $\mathrm{s}_{\mathrm{n}}{ }^{*} p<0.05$.
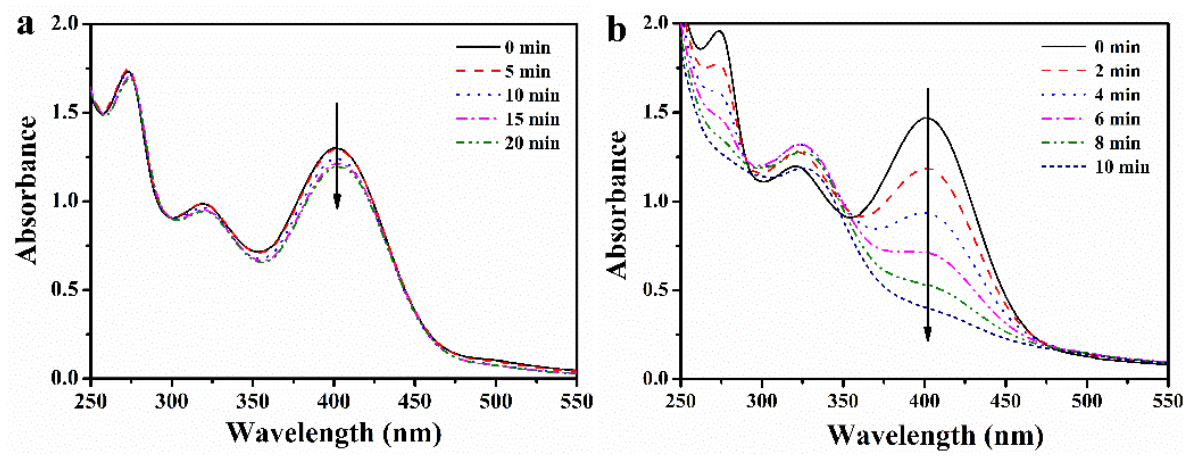

Figure 7. The UV-Vis spectra of the oxidation of morin (a) without the catalyst every 5 min and (b) with the PO-PdNPs 75 every 2 min.

Table 1. Comparison of $K_{n o r}$ and TOF of PO-PdNPs $n$ with other Pd-based catalysts in 4-NP reduction.

\begin{tabular}{|c|c|c|c|}
\hline Catalyst & $K_{\text {nor }}\left(\mathrm{s}^{-1} \mathrm{mM}^{-1}\right)$ & TOF $\left(h^{-1}\right)$ & Reference \\
\hline $\mathrm{PdP} / \mathrm{CNSs}$ & 1.4 & 504 & [2] \\
\hline $\mathrm{Pd} / \mathrm{Fe}_{3} \mathrm{O}_{4} @ \mathrm{SiO}_{2} @ \mathrm{KCC}-1$ & 2.78 & - & [26] \\
\hline $\mathrm{Pd} / \mathrm{SBA}-15$ & 0.118 & - & [27] \\
\hline$@ \mathrm{Pd} / \mathrm{CeO}_{2}$ & - & 1068 & [28] \\
\hline PO-PdNPs 75 & - & 1796 & This work \\
\hline PO-PdNPs 150 & 18.53 & - & This work \\
\hline
\end{tabular}

\subsection{Catalytic Activity of PO-PdNPs $s_{n}$ on Morin}

Morin is a polyphenol dye that has been used as a model to study the catalytic ability of precious metal nanoparticle catalysts. The catalytic activity and catalytic mechanism of PO-PdNPs $n$ were evaluated with the addition of $\mathrm{H}_{2} \mathrm{O}_{2}$ [29,30]. In a carbonate buffer with $\mathrm{pH} 9.2$, the maximum peak of the morin was $\lambda=403 \mathrm{~nm}$. Figure 7 a shows that without the addition of a catalyst, the maximum peak of morin hardly decreased within 20 min 
with $\mathrm{H}_{2} \mathrm{O}_{2}$. Figure $7 \mathrm{~b}$ shows that after adding the catalyst PO-PdNPs 55 , the absorbance at $403 \mathrm{~nm}$ decreased rapidly with time, while the absorbance at $325 \mathrm{~nm}$ gradually increased with time. This phenomenon indicated that the morin underwent catalyzed oxidation to benzofuranone [31]. After a longer time, the peak at $325 \mathrm{~nm}$ decreased again, indicating that benzofuranone was further oxidized $[32,33]$. Therefore, the experimental study of the reaction kinetics was carried out by controlling the reaction time.

To study the relationship between $k_{\mathrm{app}}$ and PO-PdNPs $\mathrm{s}_{\mathrm{n}}$ concentration, the effect of changing the concentration of $\mathrm{PO}-\mathrm{PdNPs}_{\mathrm{n}}$ on the catalytic reaction under the conditions of constant concentration of morin and $\mathrm{H}_{2} \mathrm{O}_{2}$ was measured. Figure $8 \mathrm{a}$ showed that the relationship between $k_{\text {app }}$ and the catalyst concentration was linear. With the increase of catalyst concentration, $k_{\mathrm{app}}$ became higher. The three proportions of catalysts had the same trend as follows: PO-PdNPs $s_{75}>$ PO-PdNPs $100>$ PO-PdNPs ${ }_{150}$. The $K_{\text {nor }}$ of PO-PdNPs $s_{75}$, PO-PdNPs ${ }_{100}$, and PO-PdNPs 150 were 105.77, 129.49, and $143.57 \mathrm{~s}^{-1} \mathrm{M}^{-1}$, respectively, so the catalytic activity was increased according to the order of PO-PdNPs $75<$ PO-PdNPs $100<$ PO-PdNPs $s_{150}$. This was because the particle size of PdNPs in PO-PdNPs decreased in the order of PO-PdNPs $s_{75}<\mathrm{PO}-\mathrm{PdNPs}_{100}<\mathrm{PO}-\mathrm{PdNPs}_{150}$. At the same concentration, the smaller particle size resulted in the larger specific surface area and the higher catalytic efficiency.
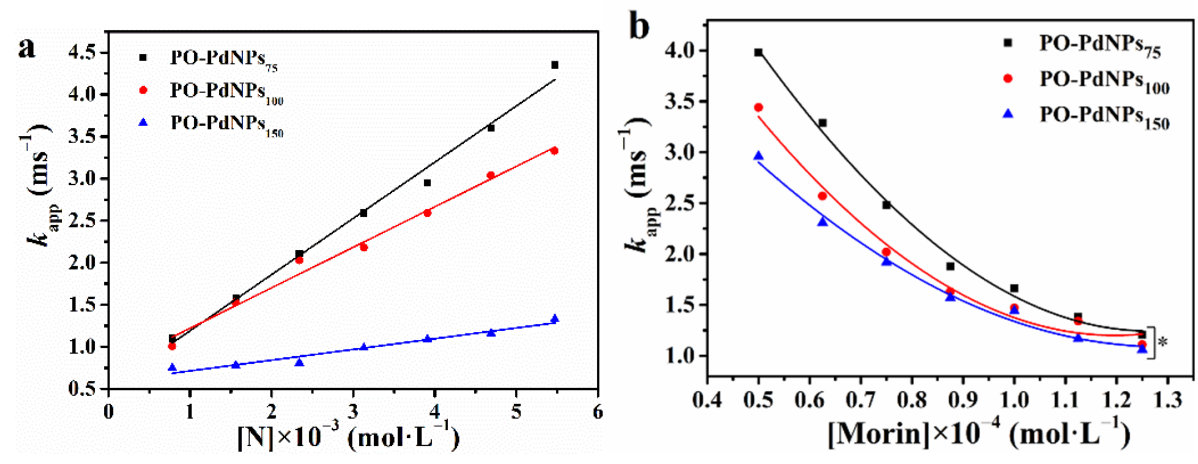

Figure 8. (a) The effect of different concentration and ratio of catalysts on the catalytic reaction $k_{\text {app }}$. (b) The effect of different concentrations of morin on the catalytic reaction $k_{\mathrm{app}}\left(\mathrm{C}_{\mathrm{H} 2 \mathrm{O} 2}=10 \mathrm{mM}\right.$, $\left.\mathrm{C}_{[\mathrm{N}]}=0.78 \mathrm{mM}\right){ }^{*} p<0.05$.

To study the relationship between $k_{\text {app }}$ and the morin concentration, this experiment monitored the process of morin reaction by fixing the $\mathrm{H}_{2} \mathrm{O}_{2}$ concentration during the reaction process. As shown in Figure $8 \mathbf{b}, k_{\text {app }}$ decreased with increasing morin concentration. This was consistent with the previously reported results of catalytic oxidation of morin by MnOx [34]. Surface coverage was the primary factor of the reaction rate that was dependent on the different concentration and adsorption constant of morin and $\mathrm{H}_{2} \mathrm{O}_{2}$. Generally, during the reaction of morin, the adsorption constant $K_{\text {morin }}$ is higher than $\mathrm{K}_{\mathrm{H} 2 \mathrm{O} 2}$. Therefore, compared with $\mathrm{H}_{2} \mathrm{O}_{2}$, morin is more easily adsorbed on the catalyst surface. As the concentration of morin increased, the active sites on the surface of noble metal nanoparticles are covered, resulting in a decrease in the active sites available for $\mathrm{H}_{2} \mathrm{O}_{2}$ adsorption, which gradually decreases the reaction rate when the concentration of morin increases.

\subsection{Catalytic Mechanism}

During the catalytic reduction of 4-NP, the Langmuir-Hinshelwood kinetics method was followed according to previous reports $[35,36]$. Similarly, the catalytic reduction of $4-\mathrm{NP}$ by PO-PdNPs $n$ should also meet the equation. 4-NP was quickly reduced to a stable intermediate 4-hydroxyaminophenol. The electrons from sodium borohydride and 4-hydroxyaminophenol ions combined on the surface of PdNPs to produce 4-AP ions, and then 4-AP ions were desorbed to form 4-AP molecules. In this process, the adsorption/desorption equilibria of all related compounds on the surface of PdNPs were rapidly 
achieved. In the oxidation process of morin by PO-PdNPs , the Langmuir-Hinshelwood kinetics method was also followed $[29,37]$.

\section{Conclusions}

In conclusion, PEI-oleic acid micelles were prepared and used to stabilize PdNPs in aqueous solution. The size of PdNPs in the PO-PdNPs $n$ was between 1.67 and $2.01 \mathrm{~nm}$ with a narrow size distribution. The PO-PdNPs $n$ maintained high stability due to its zeta potentials larger than $20 \mathrm{mV}$. In addition, the prepared PO-PdNPs $s_{n}$ effectively catalyzed the reduction of 4-NP to form 4-AP. PO-PdNPs $\mathrm{n}_{\mathrm{n}}$ also had high catalytic efficiency for morin. The catalytic ability of PO-PdNPs $n$ was higher than those of other catalysts, which could result from the small size and high stability of Pd NPs. The location of PdNPs in the PEIoleic acid micelles was good for low mass transfer resistance. The prepared PO-PdNPs has great potential applications in treating various organic contaminants in solution in the future.

Supplementary Materials: The following are available online at https:/ /www.mdpi.com/article/10 .3390 / polym13111890/s1, Figure S1: FTIR spectra of PEI-oleic acid micelles and PO-PdNPs 75 , Table S1: IR bands of the two compounds and their assignments.

Author Contributions: Conceptualization, L.W.; methodology, L.W.; investigation, X.Z.; writingoriginal draft preparation, X.L.; writing—review and editing, X.L., S.L., J.Z., W.L. and L.W.; visualization, X.Z.; supervision, L.W. All authors have read and agreed to the published version of the manuscript.

Funding: This research was funded by Natural Science Foundation of Hebei Province, grant number B2017203229, China Postdoctoral Science Foundation, grant number 2016M601284, National undergraduate Innovation and Entrepreneurship Training Program of Yanshan University, grant number S202010216074 and 202010216055.

Institutional Review Board Statement: Not applicable.

Informed Consent Statement: Not applicable.

Data Availability Statement: The data presented in this study are available on request from the corresponding author.

Conflicts of Interest: The authors declare no conflict of interest.

\section{References}

1. Dong, Z.; Le, X.; Dong, C.; Zhang, W.; Li, X.; Ma, J. Ni@Pd core-shell nanoparticles modified fibrous silica nanospheres as highly efficient and recoverable catalyst for reduction of 4-nitrophenol and hydrodechlorination of 4-chlorophenol. Appl. Catal. B 2015, 162, 372-380. [CrossRef]

2. Zhao, Z.; Ma, X.; Wang, X.; Ma, Y.; Liu, C.; Hang, H.; Zhang, Y.; Du, Y.; Ye, W. Synthesis of amorphous PdP nanoparticles supported on carbon nanospheres for 4-nitrophenol reduction in environmental applications. Appl. Surf. Sci. 2018, 457, 1009-1017. [CrossRef]

3. Ghosh, P.; Patwari, J.; Dasgupta, S. Complexation with human serum albumin facilitates sustained release of morin from polylactic-co-glycolic acid nanoparticles. J. Phys. Chem. B 2017, 121, 1758-1770. [CrossRef]

4. Zhang, X.-F.; Zhu, X.-Y.; Feng, J.-J.; Wang, A.-J. Solvothermal synthesis of N-doped graphene supported PtCo nanodendrites with highly catalytic activity for 4-nitrophenol reduction. Appl. Surf. Sci. 2018, 428, 798-808. [CrossRef]

5. Hao, Y.; Shao, X.; Li, B.; Hu, L.; Wang, T. Mesoporous $\mathrm{TiO}_{2}$ nanofibers with controllable Au loadings for catalytic reduction of 4-nitrophenol. Mater. Sci. Semicond. Process. 2015, 40, 621-630. [CrossRef]

6. Zhang, H.; Xin, X.; Sun, J.; Zhao, L.; Shen, J.; Song, Z.; Yuan, S. Self-assembled chiral helical nanofibers by amphiphilic dipeptide derived from d- or l-threonine and application as a template for the synthesis of Au and Ag nanoparticles. J. Colloid Interface Sci. 2016, 484, 97-106. [CrossRef] [PubMed]

7. Duan, X.; Xiao, M.; Liang, S.; Zhang, Z.; Zeng, Y.; Xi, J.; Wang, S. Ultrafine palladium nanoparticles supported on nitrogen-doped carbon microtubes as a high-performance organocatalyst. Carbon 2017, 119, 326-331. [CrossRef]

8. Le, X.; Dong, Z.; Li, X.; Zhang, W.; Le, M.; Ma, J. Fibrous nano-silica supported palladium nanoparticles: An efficient catalyst for the reduction of 4-nitrophenol and hydrodechlorination of 4-chlorophenol under mild conditions. Catal. Commun. 2015, 59, 21-25. [CrossRef] 
9. Deraedt, C.; Salmon, L.; Astruc, D. “Click" dendrimer-stabilized palladium nanoparticles as a green catalyst down to parts per million for efficient CC cross-coupling reactions and reduction of 4-nitrophenol. Adv. Synth. Catal. 2014, 356, 2525-2538. [CrossRef]

10. Fedorczyk, A.; Ratajczak, J.; Kuzmych, O.; Skompska, M. Kinetic studies of catalytic reduction of 4-nitrophenol with $\mathrm{NaBH}_{4}$ by means of Au nanoparticles dispersed in a conducting polymer matrix. J. Solid State Electrochem. 2015, 19, 2849-2858. [CrossRef]

11. Ma, T.; Yang, W.; Liu, S.; Zhang, H.; Liang, F. A comparison reduction of 4-nitrophenol by gold nanospheres and gold nanostars. Catalysts 2017, 7, 38. [CrossRef]

12. Fan, L.; Ji, X.; Lin, G.; Liu, K.; Chen, S.; Ma, G.; Xue, W.; Zhang, X.; Wang, L. Green synthesis of stable platinum nanoclusters with enhanced peroxidase-like activity for sensitive detection of glucose and glutathione. Microchem. J. 2021, 166, 106-202. [CrossRef]

13. Li, N.; Zhao, P.; Astruc, D. Anisotropic gold nanoparticles: Synthesis, properties, applications, and toxicity. Angew. Chem. Int. Ed. Engl. 2014, 53, 1756-1789. [CrossRef]

14. Ye, W.; Yu, J.; Zhou, Y.; Gao, D.; Wang, D.; Wang, C.; Xue, D. Green synthesis of Pt-Au dendrimer-like nanoparticles supported on polydopamine-functionalized graphene and their high performance toward 4-nitrophenol reduction. Appl. Catal. B 2016, 181, 371-378. [CrossRef]

15. Wang, L.; Yang, Q.; Cui, Y.; Gao, D.; Kang, J.; Sun, H.; Zhu, L.; Chen, S. Highly stable and biocompatible dendrimer-encapsulated gold nanoparticle catalysts for the reduction of 4-nitrophenol. New J. Chem. 2017, 41, 8399-8406. [CrossRef]

16. Veerakumar, P.; Velayudham, M.; Lu, K.-L.; Rajagopal, S. Silica-supported PEI capped nanopalladium as potential catalyst in Suzuki, Heck and Sonogashira coupling reactions. Appl. Catal. A 2013, 455, 247-260. [CrossRef]

17. Wang, L.; Zhang, X.; Cui, Y.; Guo, X.; Chen, S.; Sun, H.; Gao, D.; Yang, Q.; Kang, J. Polyethyleneimine-oleic acid micelle-stabilized gold nanoparticles for reduction of 4-nitrophenol with enhanced performance. Transit. Met. Chem. 2020, 45, 31-39. [CrossRef]

18. Xu, M.; Qian, J.; Suo, A.; Liu, T.; Liu, X.; Wang, H. A reduction-dissociable PEG-b-PGAH-b-PEI triblock copolymer as a vehicle for targeted co-delivery of doxorubicin and P-gp siRNA. Polym. Chem. 2015, 6, 2445-2456. [CrossRef]

19. Wang, L.; Zhu, L.; Bernards, M.T.; Chen, S.; Sun, H.; Guo, X. Dendrimer-based biocompatible zwitterionic micelles for efficient cellular internalization and enhanced anti-tumor effects. ACS Appl. Polym. Mater. 2019, 2, 159-171. [CrossRef]

20. Wang, L.; Zhang, J.; Guo, X.; Chen, S.; Cui, Y.; Yu, Q.; Yang, L.; Sun, H.; Gao, D.; Xie, D. Highly stable and biocompatible zwitterionic dendrimer-encapsulated palladium nanoparticles that maintain their catalytic activity in bacterial solution. New $\mathrm{J}$ Chem. 2018, 42, 19740-19748. [CrossRef]

21. Cui, T.; Li, S.; Chen, S.; Liang, Y.; Sun, H.; Wang, L. "Stealth" dendrimers with encapsulation of indocyanine green for photothermal and photodynamic therapy of cancer. Int. J. Pharm. 2021, 600, 120-502. [CrossRef] [PubMed]

22. Dong, L.; Li, R.; Wang, L.; Lan, X.; Sun, H.; Zhao, Y.; Wang, L. Green synthesis of platinum nanoclusters using lentinan for sensitively colorimetric detection of glucose. Int. J. Biol. Macromol. 2021, 172, 289-298. [CrossRef] [PubMed]

23. Ma, G.; Lin, W.; Wang, Z.; Zhang, J.; Qian, H.; Xu, L.; Yuan, Z.; Chen, S. Development of polypeptide-based zwitterionic amphiphilic micelles for nanodrug delivery. J. Mater. Chem. B 2016, 4, 5256-5264. [CrossRef] [PubMed]

24. Sun, H.; Chang, M.Y.Z.; Cheng, W.I.; Wang, Q.; Commisso, A.; Capeling, M.; Wu, Y.; Cheng, C. Biodegradable zwitterionic sulfobetaine polymer and its conjugate with paclitaxel for sustained drug delivery. Acta Biomater. 2017, 64, 290-300. [CrossRef] [PubMed]

25. Gu, S.; Kaiser, J.; Marzun, G.; Ott, A.; Lu, Y.; Ballauff, M.; Zaccone, A.; Barcikowski, S.; Wagener, P. Ligand-free gold nanoparticles as a reference material for kinetic modelling of catalytic reduction of 4-nitrophenol. Catal. Lett. 2015, 145, 1105-1112. [CrossRef]

26. Le, X.; Dong, Z.; Liu, Y.; Jin, Z.; Huy, T.-D.; Le, M.; Ma, J. Palladium nanoparticles immobilized on core-shell magnetic fibers as a highly efficient and recyclable heterogeneous catalyst for the reduction of 4-nitrophenol and Suzuki coupling reactions. J. Mater. Chem. A 2014, 2, 19696-19706. [CrossRef]

27. Morère, J.; Tenorio, M.J.; Torralvo, M.J.; Pando, C.; Renuncio, J.A.R.; Cabañas, A. Deposition of Pd into mesoporous silica SBA-15 using supercritical carbon dioxide. J. Supercrit. Fluids 2011, 56, 213-222. [CrossRef]

28. Liu, B.; Yu, S.; Wang, Q.; Hu, W.; Jing, P.; Liu, Y.; Jia, W.; Liu, Y.; Liu, L.; Zhang, J. Hollow mesoporous ceria nanoreactors with enhanced activity and stability for catalytic application. Chem. Commun. 2013, 49, 3757-3759. [CrossRef]

29. Ncube, P.; Hlabathe, T.; Meijboom, R. The preparation of well-defined dendrimer-encapsulated palladium and platinum nanoparticles and their catalytic evaluation in the oxidation of morin. Appl. Surf. Sci. 2015, 357, 1141-1149. [CrossRef]

30. Nemanashi, M.; Meijboom, R. Catalytic behavior of different sizes of dendrimer-encapsulated Au(n) nanoparticles in the oxidative degradation of morin with $\mathrm{H}_{2} \mathrm{O}_{2}$. Langmuir 2015, 31, 9041-9053. [CrossRef]

31. Ilunga, A.K.; Meijboom, R. Catalytic and kinetic investigation of the encapsulated random alloy (Pdn-Au110-n) nanoparticles. Appl. Catal. B 2016, 189, 86-98. [CrossRef]

32. Ndolomingo, M.J.; Meijboom, R. Kinetics of the catalytic oxidation of morin on $\gamma-\mathrm{Al}_{2} \mathrm{O}_{3}$ supported gold nanoparticles and determination of gold nanoparticles surface area and sizes by quantitative ligand adsorption. Appl. Catal. B 2016, 199, 142-154. [CrossRef]

33. Polzer, F.; Wunder, S.; Lu, Y.; Ballauff, M. Oxidation of an organic dye catalyzed by $\mathrm{MnO}_{\mathrm{x}}$ nanoparticles. J. Catal. 2012, 289, 80-87. [CrossRef]

34. Xaba, M.S.; Meijboom, R. Kinetic and catalytic analysis of mesoporous $\mathrm{Co}_{3} \mathrm{O}_{4}$ on the oxidation of morin. Appl. Surf. Sci. 2017, 423, 53-62. [CrossRef]

35. Gu, S.; Wunder, S.; Lu, Y.; Ballauff, M.; Fenger, R.; Rademann, K.; Jaquet, B.; Zaccone, A. Kinetic analysis of the catalytic reduction of 4-nitrophenol by Metallic Nanoparticles. J. Phys. Chem. C 2014, 118, 18618-18625. [CrossRef] 
36. Nasrollahzadeh, M.; Baran, T.; Baran, N.Y.; Sajjadi, M.; Tahsili, M.R.; Shokouhimehr, M. Pd nanocatalyst stabilized on aminemodified zeolite: Antibacterial and catalytic activities for environmental pollution remediation in aqueous medium. Sep. Purif. Technol. 2020, 239, 116-542. [CrossRef]

37. Xiao, H.; Wang, R.; Dong, L.; Cui, Y.; Chen, S.; Sun, H.; Ma, G.; Gao, D.; Wang, L. Biocompatible Dendrimer-Encapsulated Palladium Nanoparticles for Oxidation of Morin. ACS Omega 2019, 4, 18685-18691. [CrossRef] 